\title{
The Gleaner
}

Vol $16(1980)$

\section{O EPANI $\Sigma T H \Sigma$}

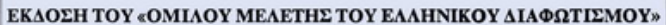

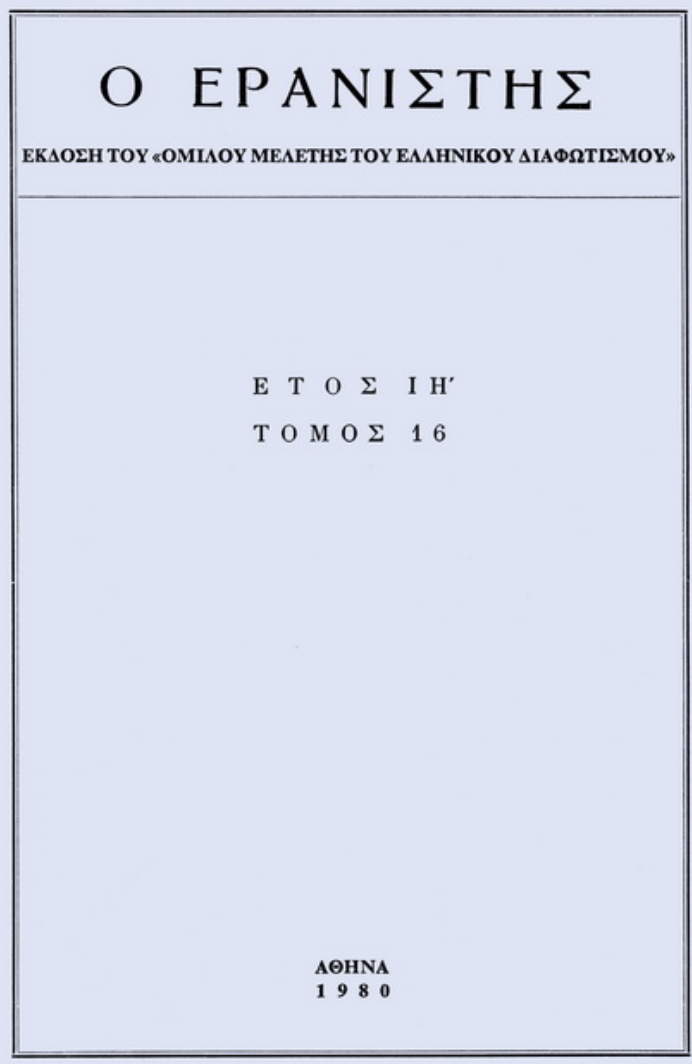

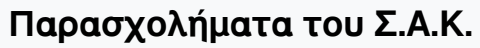

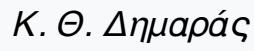

doi: $\underline{10.12681 / \mathrm{er} .340}$

To cite this article:

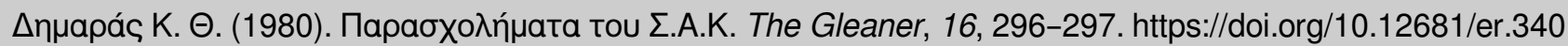




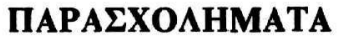

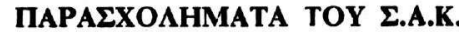

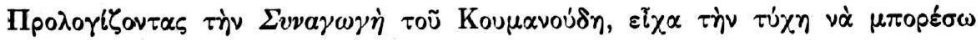

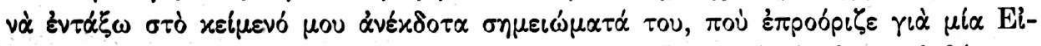

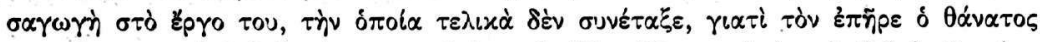

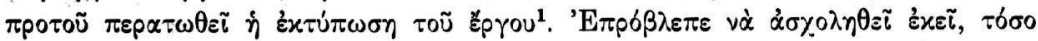

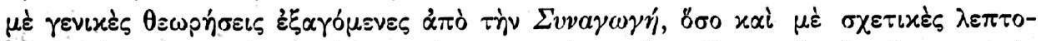

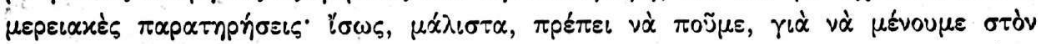

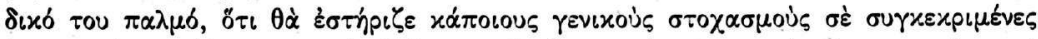

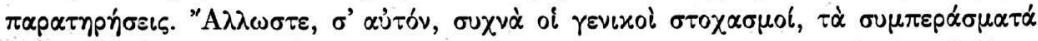

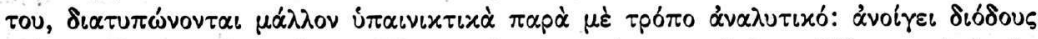

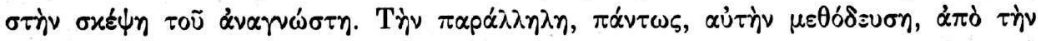

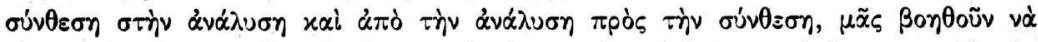

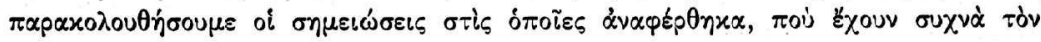

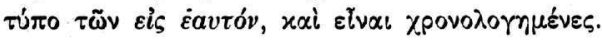

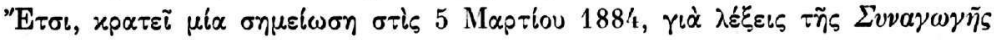

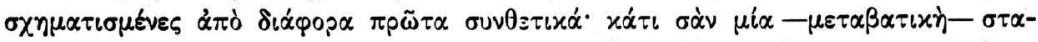

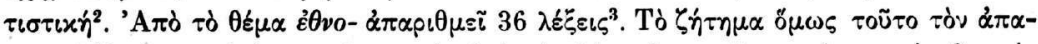

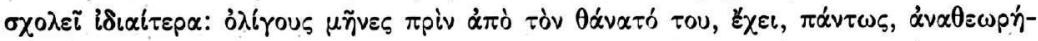

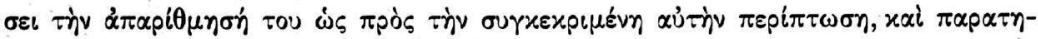

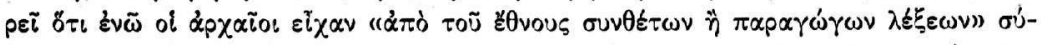

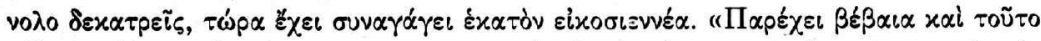

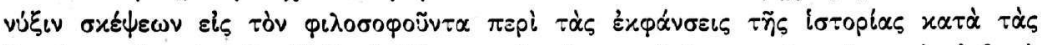

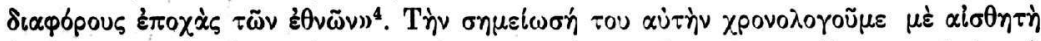

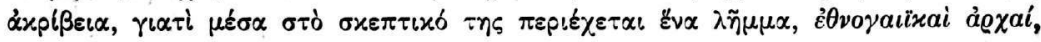

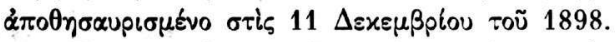

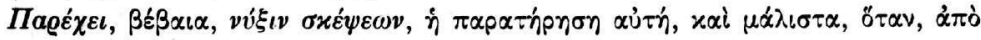

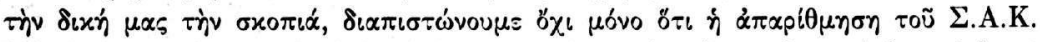

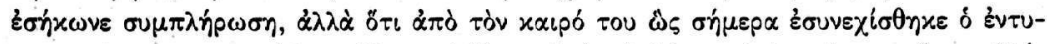

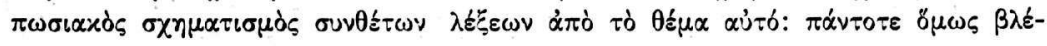

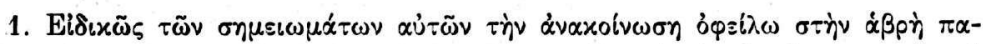

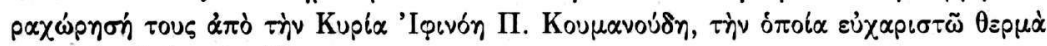

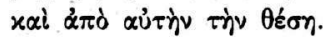

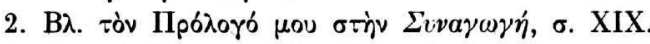

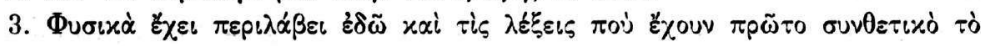
$\lambda \tilde{n} \mu \mu \alpha \varepsilon \dot{\varepsilon} \theta v i x o-$.

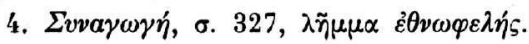




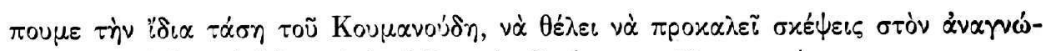

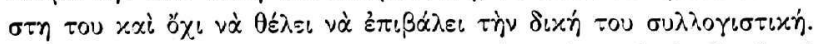

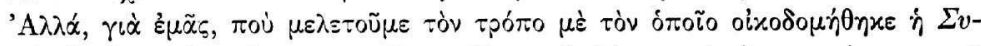

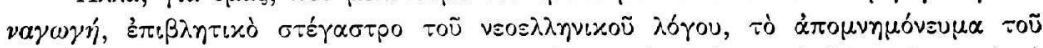

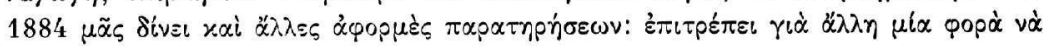

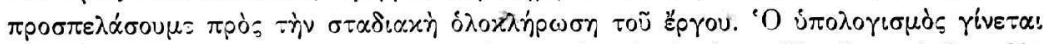

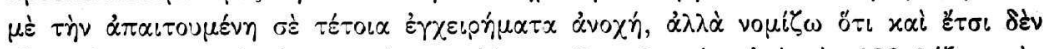

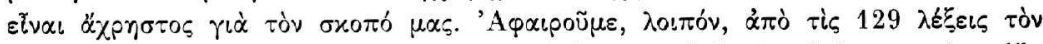

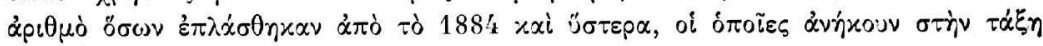

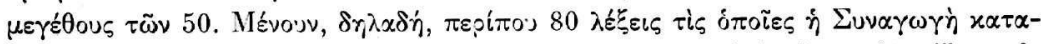

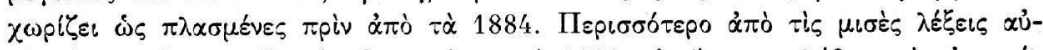

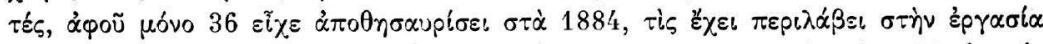

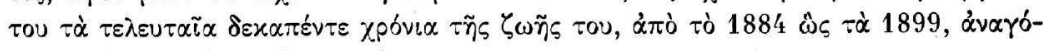

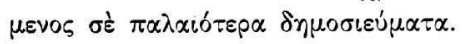

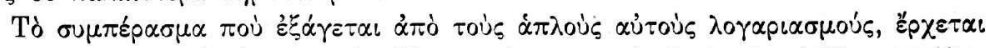

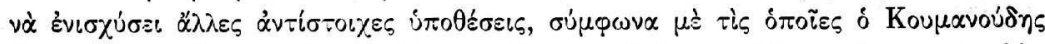

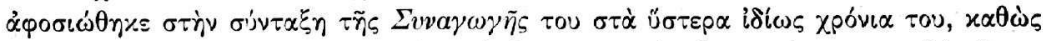

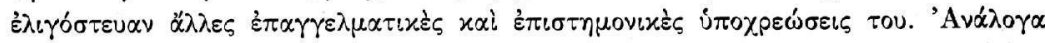

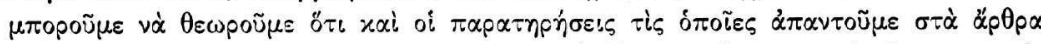

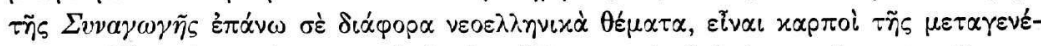

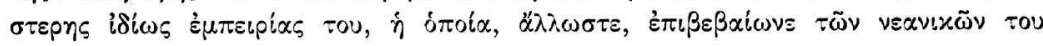

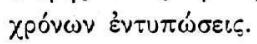

\section{K. $\Theta . \Delta \eta \mu \alpha \varrho \tilde{c} \varsigma$}

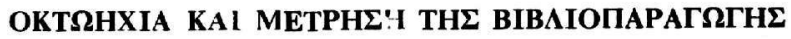

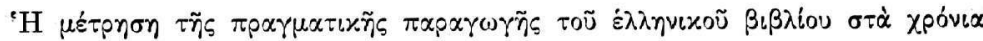

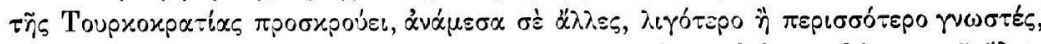

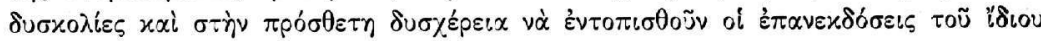

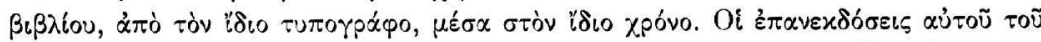

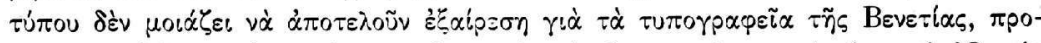

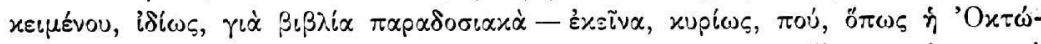

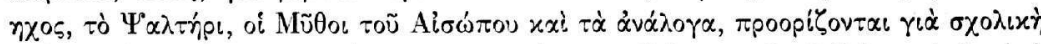

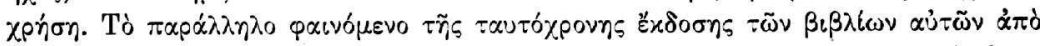

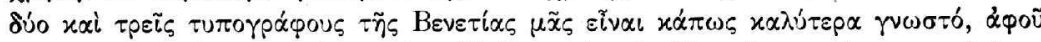

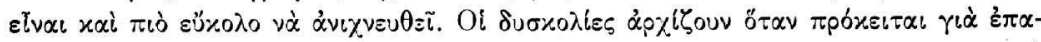

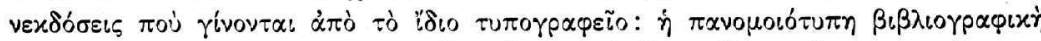

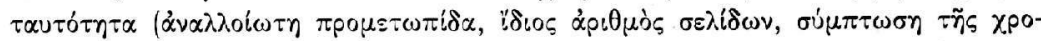

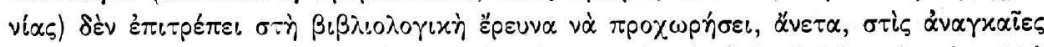

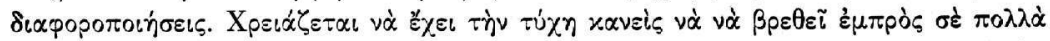

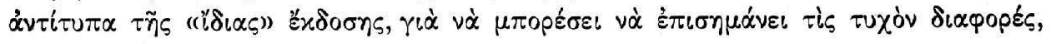

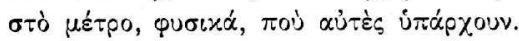

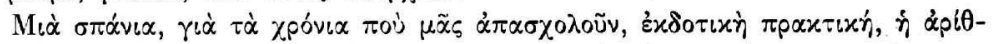

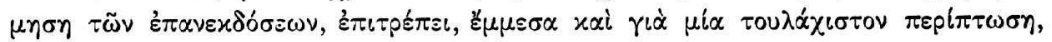

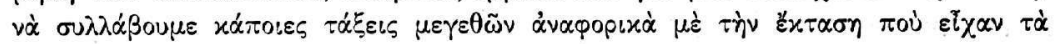

